Paper:

\title{
Post-Disaster Assessment of the Performance of Hazard Mitigation Projects: The California SMART Approach
}

\author{
Michael R. Boswell*, William J. Siembieda*, and Kenneth C. Topping** \\ -Department of City and Regional Planning, California Polytechnic State University \\ 1 Grand Ave, San Luis Obispo, CA 93407.02832, USA \\ E-mail: mboswell@calpoly.edu \\ "Topping Associates International \\ 504 Warwick Street, Cambria, CA 93428, USA \\ [Received February 23, 2010; accepted March 10, 2010]
}

California's SMART (State Mitigation Assessment Review Team) program for assessing natural hazard mitigation project performance after a disaster is a method of integrating multiple state agencies' expertise into a working tool for assessing the value of public investments in risk reduction. The intent of the SMART program is to provide the California Emergency Management Agency with information about the performance of publicly financed mitigation projects so that it can better allocate future funding and improve the overall safety of California. A key aspect of the program is the mobilization of California State University faculty and staff from across the state after a disaster in order to conduct rapid performance assessments while field data is available. In order to test the SMART system, a pilot study was conducted using the Yountville Flood Barrier Wall Project performance during a 2005 flood on the Napa River. The case validated the idea that for a flood project, a rapid evaluation could be conducted using field observations that establish the height and extent of flooding and include the project's original cost-benefit analysis. The data produced from this type of evaluation program will be valuable to state emergency management agencies trying to allocate program grants in the most effcient manner and to government agencies who want to make sure that federal dollars are being spent wisely.

Keywords: hazard, disaster, mitigation, assessment, Cal EMA, benefit-cost, California, flood

\section{Introduction}

California's SMART (State Mitigation Assessment Review Team) program for assessing natural hazard mitigation project performance after a disaster is a method of integrating multiple state agencies' expertise into a working tool for assessing the value of public investments in risk reduction. This paper describes the program's el- ements, provides a working example, and reviews the strong points and the challenges of this field method.

The State of California Emergency Management Agency (called the Governors Office of Emergency Services prior to 2009) developed the SMART program during the update of their 2007 update of the State MultiHazard Mitigation Plan (SHMP). The plan update and development of the SMART program were done in cooperation with a research team at the California Polytechnic State University (Cal Poly), which is part of the public California State University (CSU) system. ${ }^{1}$ The SMART system is modeled after the already in-place Cal EMA Safety Assessment Program (SAP) system, which provides preliminary damage estimates after disaster, and the recently completed FEMA "Loss Avoidance Study: Southern Califormia Flood Control Mitigation" [1]. The intent of the SMART program is to provide the California Emergency Management Agency (Cal EMA) with information about the performance of publicly financed mitigation projects so that it can better allocate future funding and improve the overall safety of California. A key aspect of the program is to mobilize CSU faculty and staff from across the state after a disaster in order to conduct rapid performance assessments while field data is available and local emergency managers and other officials are available for interviews.

In the fields of planning and public policy, monitoring and evaluation of implementation is a well established ideal of practice. Unfortunately, actual practice has not met this ideal. Mileti discusses the problem of the lack of good data on disaster losses and costs [2]. Speaking of monitoring and evaluating loss reduction through hazard mitigation, he states that "there is a woefully small amount of that kind of information available today" [2]. Moreover, despite the fact that federal and state governments have implemented mitigation grant programs, to our knowledge none of them are systematically tracking the economic, environmental, or social effectiveness of those programs.

1. The authors of this paper are the three principle investigators of the research team. 


\section{The SMART System}

The objectives of the SMART system are to assess the outcome of previously funded mitigation projects in a disaster area by: 1) ascertaining loss avoidance performance at a given level of intensity of an event, and 2) identifying the effectiveness of mitigation practices. This is done by on-site review and documentation of loss avoidance based on the project Benefit Cost Analysis (BCA). The SMART system has value in assisting Cal EMA in preparing the disaster proclamation's of new governors and in requesting federal declarations by including loss avoidance data as part of those processes.

Cal EMA administers several federal hazard mitigation grant programs. Over the past decade tens of millions of dollars have been invested in mitigation efforts. As part of the Enhanced Plan criteria for State Hazard Mitigation Plans, the U.S. Federal Emergency Management Agency (FEMA) requires that Cal EMA conduct an assessment of completed mitigation actions and establish a record of the effectiveness (actual cost avoidance) of the mitigation actions. In order to document actual loss avoidance, $\mathrm{Cal}$ EMA must first identify projects that have mitigated hazard events and then assess what losses were avoided by the implementation of the mitigation project. Although each mitigation project was approved with a BCA that established potential loss avoidance, until an actual hazard event has occurred it is impossible to establish actual loss avoidance. In effect, the SMART system is an empirical check of the BCA (i.e., did the project provide the benefits anticipated in the BCA). The BCA is a type of event modeling; thus, SMART provides information to calibrate the model parameters.

\subsection{Participants}

Cal EMA designates a SMART Coordinator within the Hazard Mitigation Planning Branch. The Coordinator has the following responsibilities:

- Statewide coordination and implementation of SMART system

- SMART member selection, training, and certification

- Monitor situation reports for potentially affected mitigation projects

- Direct activation of the SMART system

- Liaison with local emergency management officials

- Coordinate Cal EMA resources with team in the field

- Oversee assessment reporting

- Establish and operate training program

- Issue registration and identification cards, as required

- Annual verification of team member lists
The SMART membership is comprised of CSU faculty and staff with appropriate knowledge in hazard mitigation. Each field team has at least two members and additional members may be added if required due to the scope or the complexity of the assessment. The two required members are the SMART Lead and the SMART Hazard Specialist. The SMART Lead liaisons with the Cal EMA SMART Coordinator, manages the team in the field, analyzes the BCA, and coordinates the assessment and report writing. The SMART Hazard Specialist provides expertise in a particular hazard related to the event (e.g., flood, fire, earthquake) and supports the Lead. All team members have the ability to inspect mitigation projects and rapidly identify how the project works, determine the assets protected through the mitigation projects, and to inspect a project and, based on knowledge and experience, make a judgment on the loss avoidance provided by the project.

The CSU system will have campus-based SMART team locations throughout the state. The CSU has 23 locations throughout Califormia and a faculty and staff with expertise in conducting loss avoidance estimation. At different campuses, SMART teams with expertise in different types of disaster events could be in place and available to go to a location with short notice. Moreover, the CSU system has a central office of Risk Management that could serve a networking role for coordination of this effort. In addition to faculty members with wide-ranging expertise, each CSU campus has three groups that can assist with coordination of SMART team deployment, including the Risk Management Office, the Emergency Management Coordinators (often in the campus police department), and the Facilities Group.

Training for SMART members is provided by $\mathrm{Cal}$ EMA and other state agencies having specialized knowledge in different types of disasters. For example, the Department of Water Resources would assist with training and assessment documentation related to floods. Cal EMA staff will provide base forms for use by SMART team members similar to those used for preparing preliminary damage assessments. SMART Leads receive BCA training and achieve proficiency in manipulating the models.

\subsection{Activation}

The Cal EMA SMART Coordinator regularly compares situation reports and emergency declarations with the geo-coded database of mitigation projects. When areas of co-occurrence are located, the mitigation project file is reviewed for potential SMART review. If a project is deemed to have potential loss avoidance, the coordinator contacts the local jurisdiction to coordinate the SMART activation. Emergency management officials in the local jurisdiction must certify to Cal EMA that response operations (e.g., search and rescue) are complete, the area is safe for the team, and that the team will not be interfering with recovery operations, before Cal EMA will allow the team to enter the field. During this time, the coordinator 
is also notifying the SMART members of the event, establishing who is available to participate, and collecting the Cal EMA provided data. Once local clearance is gained, the coordinator appoints the SMART members, provides mitigation project documents, and establishes contact between the SMART Lead and the appropriate local emergency management officials.

The timing of activation occurs as soon as the response operations are complete and the safety and efficiency of the team can be assured. There is a need to get the team in the field in a timely matter so that evidence is preserved and memories are fresh. In addition, the information from the mitigation assessments may be useful in supplying evidence for obtaining a federal disaster declaration. Timing of entry into the field is similar to that of the FEMA Preliminary Damage Assessment teams.

\subsection{Functions}

The SMART team reviews mitigation project documents, goes to the disaster location(s), contacts appropriate local emergency management officials, and conducts assessments of previously funded mitigation projects with a primary focus on estimating loss avoidance.

Prior to arrival at the local jurisdiction, the SMART members review mitigation project documents provided by the Cal EMA SMART Coordinator. The Coordinator provides the following documents to the team:

- Project information from the Cal EMA Mitigation Grants Management System

- Project application (or summary) and any significant modifications

- Original obligation letter and any significant modifications

- Project cost-benefit analyses

- Project California Environmental Quality Act documents (or summary)

- Relevant maps and diagrams of the projects

- Photos of the finished projects

- Map and/or satellite photo showing extent of disaster

- Stafford Act Public Assistance data on prior disaster events in areas of similar type and scale

Upon arrival in the local jurisdiction, the SMART members will register with the local emergency management official identified by the Cal EMA SMART coordinator and receive a situation briefing with local emergency management officials. The team members only gather and analyze data and do not assist in response/recovery operations and only enter structures with authorized local personnel.

The team primarily uses the BCA data to estimate physical loss avoidance; however, a changed asset profile (e.g., new buildings in a mitigation area) may necessitate additional field data collection. In addition, interviews are conducted with key local personnel regarding loss avoidance. The team analyzes the project in terms of its BCA and other factors such as injury avoidance, loss of life, and environmental degradation. For example, if the funded project was a real property acquisition in a floodplain and a flood event occurs, then the loss avoidance would be calculated as non-payment of damages based on current replacement costs. If a house was valued at $\$ 100,000$ but was not lost, then this amount is a non-payment savings to the government. Once an assessment is completed, the SMART report is sent back to Cal EMA where Cal EMA staff review it for accuracy and completeness.

There are two types of assessments performed: Rapid Evaluation and Detailed Evaluation. Rapid Evaluation is an initial assessment conducted in the field and completed within one week. The objective is to minimize labor and quickly provide evidence to Cal EMA that can be used in disaster declaration requests and other short-term data needs. Detailed Evaluation is completed after the Rapid Evaluations, but only when requested by Cal EMA, in order to provide additional detail for complex projects.

The Yountville Pilot Case (see below) showed that for a flood project, a Rapid Evaluation could be conducted using field observations that establish the height and extent of flooding, in conjunction with the project BCA. Earthquake BCAs have a similar format and would require establishing the Peak Ground Acceleration (PGA in \% of g) at the project site. Determining the ground shaking at a site after an earthquake is a function of the proximity of seismometers and how well are they distributed around the site. Generally, the recorded motions are released within a couple weeks of an event, but the data will be regional, not building specific. But reliable, site-specific measures are possible, particularly in populated regions where there is a high density of seismometers operated by the CGS and/or USGS. Thus Rapid Evaluations can be conducted for earthquake projects.

Wildfires are very different in nature and in how their BCAs are calculated and the same approach cannot be used. Wildfire mitigations may eliminate or significantly reduce the scale of the natural event, unlike earthquakes and weather-related flooding. This makes calculating avoided losses a much more hypothetical exercise. Since wildfire mitigation projects are very limited in number in California, it is reasonable to expect that these will usually require Detailed Evaluations.

\section{The Pilot Project}

In order to test the SMART system we conducted a pilot study using the Yountville Flood Barrier Wall Project (Project) located in Yountville, CA. The Project cost \$4.2 million, with $\$ 3.2$ million from federal funds administered by the State of California. The estimated benefits of the project are $\$ 6$ million. The objectives of the SMART pilot study are: 


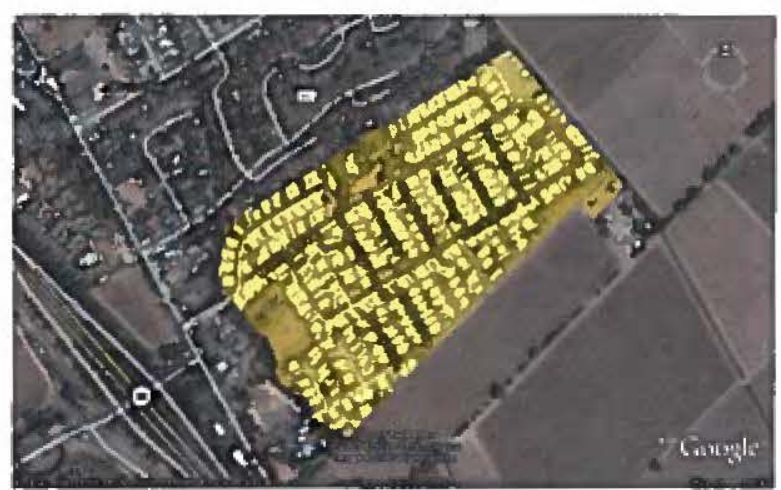

Fig. 1. Area protected by the flood barrier wall. Source: Google Earth ${ }^{\mathrm{TM}}$.

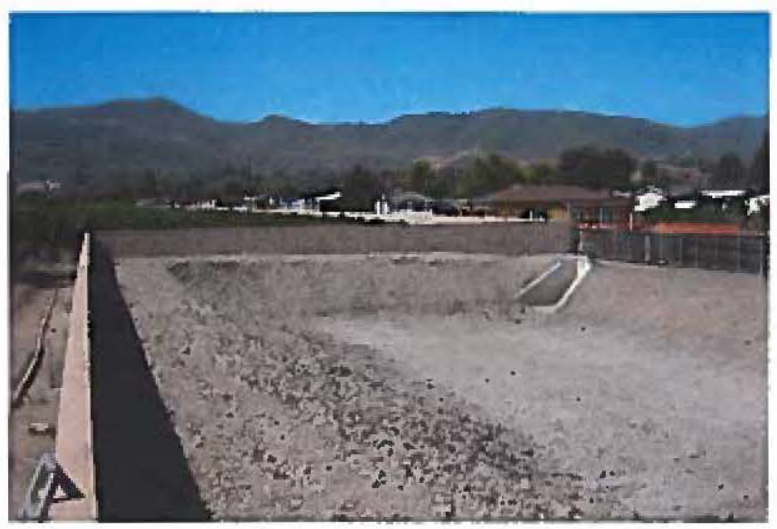

Fig. 2. Yountville flood barrier wall and detention pond (east comer of project). Source: Michael R. Boswell (August 22, 2007).

1 Determine the "loss avoidance" for the Yountville Flood Barrier Wall Project using a Rapid Assessment approach

2 Refine SMART procedures for entering the field and gathering data

The Yountville Flood Barrier Wall Project was chosen for the pilot for three reasons:

1 The Project is less that three years old, thus data were easy to obtain.

2 The Project was affected by a documented disaster, thus the forecast estimates of loss avoidance could be "tested" by a real-world event.

3 The Project scope was relatively narrow, thus suitable for a pilot case.

\subsection{Project and Disaster Event}

The Project is a flood barrier wall that encloses two mobile home parks (Gateway \& Rancho) totaling 314 units on the southern end of town (see Fig. 1). In addition,

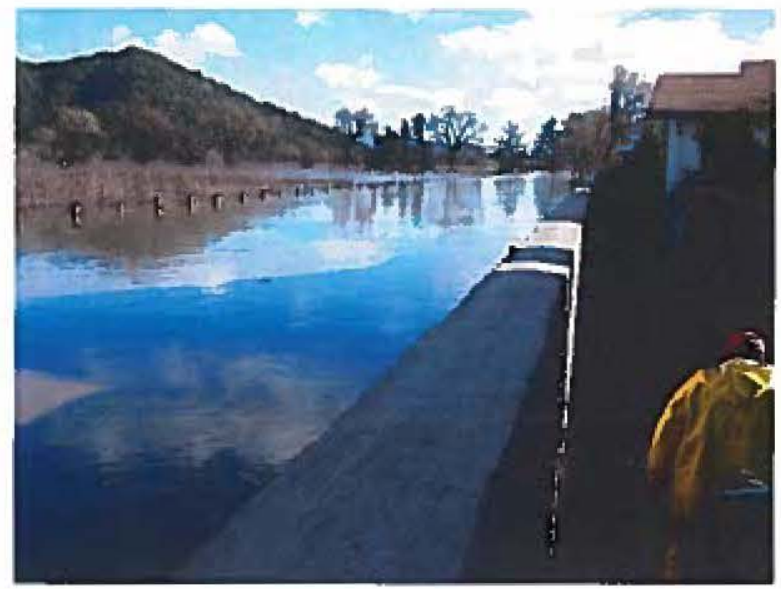

Fig. 3. Floodwaters at maximum height on the Yountville flood barrier wall, December 31, 2005. Source: City of Yountville.

inside the wall is a detention pond and pump system to remove rainfall and seepage that enters the parks (see Fig. 2). The Project is designed to protect the parks from a more than 100 -yr flood event from the Napa River located approximately 2000 ' to the east. The parks were located in the 100-yr floodplain with base flood elevations in the $85^{\prime}$ to $86^{\prime}$ range and with first floor elevations of units ranging from $83.6^{\prime \prime}$ to $86.6^{\prime}$.

On December 31, 2005, the Napa River experienced major flooding from a weather system that brought heavy rain throughout the Napa Valley, including 7.8 inches in Yountville. This event received a Presidential Disaster Declaration (DR 1628). Floodwaters overtopped private levees along the river and flowed westward toward the Project. The Project area received floodwaters that reached a maximum height of $84.5^{\prime}$ elevation, which is $4^{\prime}$ below the top of the flood barrier wall (see Fig. 3). No floodwater entered the mobile home park, thus the Project was successful at mitigating the flood hazard. Previous floods in 1986, 1995, and 1997, prior to the flood barrier wall, caused considerable damage to the mobile home parks.

\subsection{Determine Loss Avoidance}

The first objective of the pilot study was to determine the "loss avoidance" of the Project. In other words, what disaster damages were avoided because the flood barrier wall was in place around the mobile home park? The "loss avoidance" study uses both qualitative and quantitative data and depends primarily on information in the BCA used to justify the project. Further, the study was a Rapid Evaluation completed in a few days, and which provided a rough estimate of loss avoidance. This supports the short timeframes established for the SMART system.

The following steps were followed to determine the loss avoidance from the $12-05$ flood event due to the flood barrier wall mitigation:

1 Obtain barrier elevation 
2 Establish maximum flood elevation

3 Establish first floor elevations (FFE) for each unit type/category

4 Obtain flood damage estimates from BCA based on "before mitigation" data for established flood elevation for each structure type

5 Calculate "loss avoidance" and adjust for inflation using FEMA tool

6 Add additional avoided losses not considered in BCA (e.g., emergency management costs)

7 Subtract new losses resulting from the project

All data sources are documented and, where possible, validated by multiple sources.

\section{(1) Obtain barrier elevation}

Elevation of the barrier was overtopped 88.5 feet above sea-level (established from BCA analysis and construction drawings.)

\section{(2) Establish maximum flood elevation}

The maximum flood elevation is 84.5 feet above sealevel (established by field observation and photographic evidence as shown in Fig. 3).

\section{(3) Establish first floor elevations (FFE)}

The units in the mobile home parks were categorized by size (single or double wide) and FFE. Since the FFE is reported as a range, the "conservative" or higher end of the elevation range was used for purposes of the BCA.

\section{(4) Obtain flood damage estimates}

The BCA shows Building Damages, Contents Damages, and Displacement Costs by flood depth for each mobile home unit category based on size (single or double wide) and estimated dollar values (for an example, see Table 1).

\section{(5) Calculate "loss avoidance"}

The flood depth for each unit category is estimated by subtracting the FFE from the maximum flood elevation. The "Scenario Damages Before Mitigation (\$ per event)" table from the BCA is read to obtain the total dollar estimates by unit category. These are multiplied by the number of units, summed, and adjusted for inflation using the FEMA BCA Inflation Calculator (see Table 2). The event caused no damages to the mobile home park, but if they had occurred they would need to be subtracted from this subtotal. These damages could be obtained from the Preliminary Damages Assessments conducted by FEMA teams or estimated from the BCA.

\section{(6) Add additional avoided losses}

The BCA did not consider avoided emergency management costs (Public Assistance, Cat. A \& B). Thus, two methods were used to determine these avoided losses. The first method was examination of these costs in prior
Table 1. Example of double-wide mobile home unit scenario damages.

\begin{tabular}{|l|l|l|l|}
\hline \multicolumn{4}{|l|}{$\begin{array}{l}\text { SCENARIO } \\
\text { MITIGATION } \\
\text { (\$ per event) }\end{array}$} \\
\hline $\begin{array}{l}\text { Flood } \\
\text { Depth }\end{array}$ & $\begin{array}{l}\text { Building } \\
\text { Damages }\end{array}$ & $\begin{array}{l}\text { Contents } \\
\text { Damages }\end{array}$ & $\begin{array}{l}\text { Displacement } \\
\text { Costs }\end{array}$ \\
\hline-2 & $\$ 0$ & $\$ 0$ & $\$ 0$ \\
\hline-1 & $\$ 0$ & $\$ 0$ & $\$ 0$ \\
\hline 0 & $\$ 7,601$ & $\$ 2,699$ & $\$ 0$ \\
\hline 1 & $\$ 41,807$ & $\$ 14,847$ & $\$ 13,968$ \\
\hline 2 & $\$ 95,016$ & $\$ 20,246$ & $\$ 16,881$ \\
\hline 3 & $\$ 95,016$ & $\$ 20,246$ & $\$ 16,881$ \\
\hline 4 & $\$ 95,016$ & $\$ 20,246$ & $\$ 16,881$ \\
\hline 5 & $\$ 95,016$ & $\$ 20,246$ & $\$ 16,881$ \\
\hline 6 & $\$ 95,016$ & $\$ 20,246$ & $\$ 16,881$ \\
\hline 7 & $\$ 95,016$ & $\$ 20,246$ & $\$ 16,881$ \\
\hline 8 & $\$ 95,016$ & $\$ 20,246$ & $\$ 16,881$ \\
\hline$>8$ & $\$ 95,016$ & $\$ 20,246$ & $\$ 16,881$ \\
\hline
\end{tabular}

Source: Cal EMA Yountville Flood Barrier Wall Report of Benefit-Cost Analysis (OES \#154A) dated 11-22-04.

events. There were three prior disasters in Yountville for which Public Assistance funds were disbursed (see Table 3). Since these show "emergency protective measures" taken before the mobile home parks were protected by the flood barrier, they can be used to estimate avoided losses. The three Public Assistance expenditures are very similar - ranging from $\$ 4,147$ to $\$ 9,870$ in 2006 dollars - and thus can be considered reliable measures. For DR 1203 , the costs are specifically associated with the mobile home parks so they may be the most accurate. Nevertheless, the highest number is used in this analysis.

The second method for determining these avoided losses was interviews with local emergency management officials. They estimated avoided emergency management costs (Public Assistance, Cat. A \& B) at $\$ 1,000,000$. This seems quite high compared to the Public Assistance data, but it may be due to miscommunication in the interview process. Since this estimate may not be reliable it is not used in this analysis.

No other avoided losses were determined from the field observations or interviews. For example, no new development had occurred in the park.

\section{(7) Subtract new losses resulting from the project}

An assessment of the immediate upstream and downstream areas of the Project was conducted to determine if damages had occurred which might be attributable to the flood barrier wall. None were identified from interviews with local officials.

The total loss avoidance estimated for the 12-05 Napa River flood due the Yountville Flood Barrier Wall Project is approximately $\$ 1.63$ million. Table 4 summarizes the Loss Avoidance calculations. This is considered a conservative estimate. The depth damage functions in the BCA are very sensitive between 0 and 2 feet of water above the FFE, which were the levels of flooding experienced dur- 
Table 2. Loss avoidance calculations.

\begin{tabular}{|c|c|c|c|c|c|c|c|}
\hline FFE Category & 2-wide Units & 1-wide Units & FFE & Flood Depth & Scenario Damages & & TOTAL \\
\hline \multicolumn{8}{|l|}{ Rancho MHP } \\
\hline $84.1-84.6$ & 42 & 0 & 84.6 & 0 & $\$ 10,301$ & & $\$ 432,642$ \\
\hline $83.7-84$ & 5 & 0 & 84.0 & $T$ & $\$ 70,621$ & & $\$ 353,105$ \\
\hline $0-83.6$ & $\overline{0}$ & 10 & 83.6 & 1 & $\$ 58,863$ & & $\$ 588,630$ \\
\hline \multicolumn{8}{|l|}{ Galeway MHP } \\
\hline \multirow[t]{3}{*}{$0-84.7$} & & 23 & 84.7 & 0 & $\$ 8,698$ & & $\$ 200,054$ \\
\hline & & & & & \multirow{2}{*}{ Loss Avoidance } & Subtotal & $\$ 1,574,431$ \\
\hline & & & & & & TOTAL (inflated) & $\$ 1,621,664$ \\
\hline
\end{tabular}

Table 3. Public Assistance (PA) costs for three flood disasters in Yountville.

\begin{tabular}{|l|l|l|l|l|l|}
\hline Disaster Number & Disaster Description & Date/ Period & PA Description & PA Costs & $\begin{array}{l}\text { PA Costs } \\
\text { (2006 dollars) }\end{array}$ \\
\hline DR 979 & Late winter storm & Winter 1992 & $\begin{array}{l}\text { Emergency response for various } \\
\text { locations (sandbagging, traffic } \\
\text { control, emergency sheiter, etc.) }\end{array}$ & $\$ 6,744$ & $\$ 9,870$ \\
\hline DR 1044 & Winter storms & Winter 1995 & $\begin{array}{l}\text { emergency protective measures } \\
\text { town-wide }\end{array}$ & $\begin{array}{l}\$ 3,293 \\
\text { parks and food and water for 12 } \\
\text { hours }\end{array}$ & $\$ 4,147$ \\
\hline DR 1203 & $\begin{array}{l}\text { Severe winter storms } \\
\text { and flooding }\end{array}$ & $2 / 2-4 / 30,1998$ & $\begin{array}{l}\text { Evacuation of mobile home } \\
\text { p5,292 }\end{array}$ & $\$ 7,131$ \\
\hline
\end{tabular}

Source: Cal EMA Hazard Mitigation Branch provided Damage Survey Reports

ing this event. By making an assumption that either errors in estimating FFE or maximum flood elevation result in flood depths that are one foot higher, the damages in this scenario jump from $\$ 1.6$ million to $\$ 6.2$ million. Thus the Loss Avoidance could be as high as $\$ 6.2$ million under "worst case" assumptions.

In March 2007, FEMA released the "Loss Avoidance Study: Southern California Flood Control Mitigation" report. The study examined five flood mitigation projects that had experienced flood events and determined the loss avoidance. Although the purpose was similar, the study differed in two principle ways. First, instead of establishing flood elevation from field measurements, the study used hydrologic flood models based on rainfall data to estimate flood elevations. Second, instead of taking structural damage and value estimates from the BCA, the study primarily used HAZAUS-MH to estimate these values. In the conclusions of the study, FEMA reports a "Return on Mitigation Investment"(ROI) percentage. This is derived by dividing the losses avoided by the project investment (cost). For the five projects the ROI ranged from $4 \%$ to $86 \%$ with an average of $39 \%$. The Yountville Project had a ROI of $39 \%$.

Several challenges and issues arose in completing the loss avoidance Rapid Assessment:

- Since emergency management costs are not documented in the BCA they are difficult to determine. Estimates from interviewing local officials were much higher in magnitude than Public Assistance data from prior events indicating that the interview approach may not establish accurate esti-
Table 4. Yountville flood barrier wall project loss avoidance.

\begin{tabular}{|l|l|r|}
\hline Category & Source & Loss Avoidance \\
\hline Scenario Damages & BCA & $\$ 1,621,664$ \\
\hline $\begin{array}{l}\text { Emergency Management } \\
\text { (PA, Cat. A \& B) }\end{array}$ & Prior PA costs & $\$ 9,870$ \\
\hline TOTAL & & $\$ 1,631,534$ \\
\hline
\end{tabular}

mates. Such costs, however, are real and could be assigned a value, for example, $10 \%$ of damages, or some standard range established from multiple event databases.

- All of the BCA calculations were not included in the project file and had to be recreated by the team. Since the raw data was in the file, this proved to be a relatively easy exercise.

- City of Yountville officials noted that the SMART team could have entered the area as soon as $\mathbf{2 4}$ hours after the flood event.

- Since this project had a significant change in scope, the Cal EMA project file was exceptionally large. This slowed down identification of needed documents and data.

- Some of the mobile homes have been elevated subsequent to construction of the flood barrier wall. This raises the question of whether their new heights should be recalculated and considered in the loss avoidance calculations. 
- Retired people and very frail elderly, some with major medical issues, primarily occupy these mobile homes. Avoiding evacuation is important to the local emergency services community. It lowers loss of life, lowers injury levels, is less costly, and requires less follow up to track and relocate the evacuees. This factor was not built into the BCA, but has become a central benefit stream to the occupants and to emergency services. Stability of in-place populations does have loss avoidance value.

- The primary value of on-site talks with local officials is the gathering of direct information about the project that is not documented.

\section{Conclusion}

This study shows that post-disaster rapid evaluation of mitigation actions can be achieved with low financial and time costs. The procedure demonstrates an effective use of file data (within an agency), field measurement, and interview data to construct an assessment. Since the process is based on federal documentation requirements for hazard mitigation activities it should also be replicable across the U.S. Thus, this method can support an effort at collection of systematic national data. Such data can be used, for example, in constructing project rankings for local hazard mitigation plans. The data produced from this type of evaluation program will also be valuable to state emergency management agencies trying to distribute grants in the most efficient manner and to government agencies who want to make sure that federal dollars are being spent wisely. The SMART system provides evidence that integrated efforts among govemment agencies can yield effective results and is an argument for breaking down "stove pipe" efforts in state and local government.

\section{Acknowledgements}

The author would like to thank the following people for their assistance in the pilot project: Robb Eric S. Moss, PhD. P.E. Cal Poly; Ken Worman Program Manager, Cal EMA; Julie Norris, Sr. Emergency Services Coordinator, Cal EMA; James Hartwig, Emergency Services Coordinator, Cal EMA; Myke Praul, Public Works Director/Town Engineer, City of Yountville; Don Moore, Wastewater System Supervisor, City of Yountville.

\section{References:}

[1] Federal Emergency Management Agency, "Loss avoidance study: Southern California flood control mitigation," HMTAP Task Order 393, April 2007.

[2] D. S. Mileti, "Disasters by design," Washington, D.C.: Joseph Henry Press, 1999.

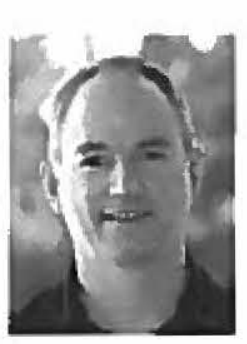

\section{Name:}

Michael R. Boswell, Ph.D. AlCP

Affiliation:

Associate Professor in City \& Regional Plan. ning, California Polytechnic State University

Address:

I Grand Ave, San Luis Obispo, CA 93407-02832, USA

Brief Career:

1991 Master of Science in Planning. The Florida State University

1998 Joined faculty of City \& Regional Planning at California Polytechnic State University

$2000 \mathrm{Ph} . \mathrm{D}$. in Planning. The Florida State University

Selected Publications:

- Stacey Swearingen White and Michael R. Boswell, "Stormwater Quality and Local Government Innovation," Journal of the American Planning

Association. Vol.73, No.2, pp. 185-193, 2007.

- Stacey Swearingen White and Michael R. Boswell, "Planning for Water Quality: Implementation of the NPDES Phase II Program in California and Kansas." Journal of Environmental Planning and Management, Vol.49, No.1, pp. 14I-160, 2006.

- Michael R. Boswell, Robert E. Deyle, Richard A. Smith, and E. Jay

Baker. "A Quantitative Method for Estimating Public Costs of Hurricanes." Environmental Management, Vol.23, No.3, pp. 359-372, 1999.

Academic Societies \& Scientific Organizations:

- American Planning Association

- Association of Collegiate Schools of Planning

- American Institute of Certified Planners

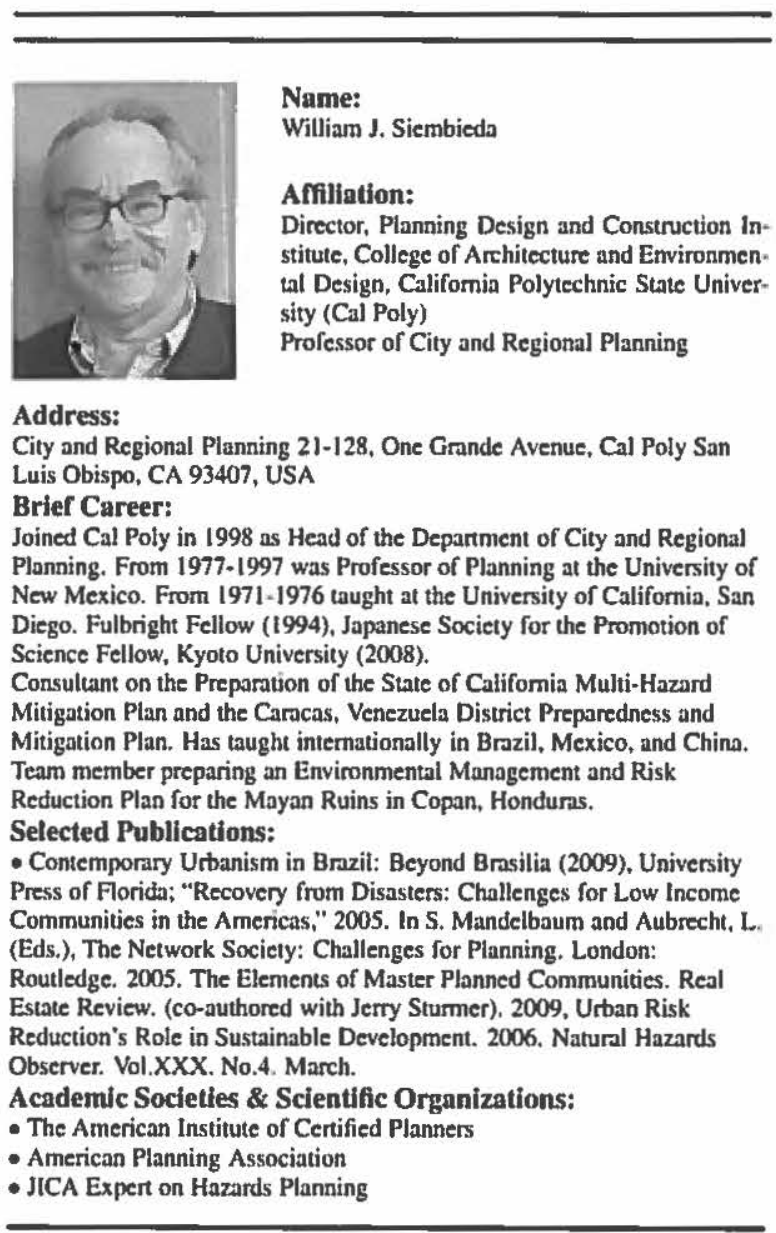




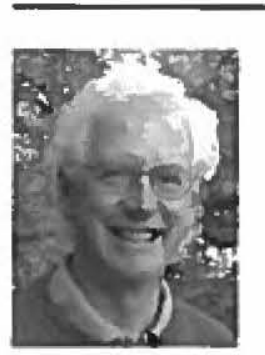

\section{Name:}

Kenneth C. Topping. FAICP

\section{Affiliation:}

President, Topping Associates International

Address:

504 Warwick Street, Cambria, CA 93428, U.S.A.

Brief Career:

1986-1990, Planning Director, City of Los Angeles, California

1991-1997, Principal, Topping Jaquess Consultants, Pasadena. Califomia

1997-2001, General Manager, Cambria Community Services District,

Cambria, California

2002-2004, Visiting Professor, Center for Research in Disaster Reduction

Systems, Disaster Prevention Research Institute, Kyoto University, Kyoto,

Japan

2004-present, President, Topping Associates International, Cambria,

Califomia

2004-present. Lecturer, California Polytechnic University, San Luis

Obispo, California

2006-present, Project Director, California Multi-Hazand Mitigation PJan

Revision Project

Selected Publications:

- "Planning for Post-Disaster Recovery and Reconstruction," American

Planning Association and FEMA, PAS Report 483/484, 1998. Co-authored

with J. Schwab et al.

- "Rebuilding Communities Following Disaster: Lessons from Kobe and

Los Angeles," Built Environment, Vol.32, No.4, November 2006.

Co-authored with R. Olshansky and L. Johnson.

- "Toward a National Disaster Recovery Act of 2009," Natural Hazards

Observer, January 2009.

- "Integrating Hazard Mitigation into Local Planning," American Planning Association and FEMA (forthcoming). Co-authored with J. Schwab et al.

Academic Societies \& Scientific Organizations:

- American Planning Association (APA)

- Board of Directors, Journal of Disaster Research

- College of Fellows. American Institute of Certified Planners (FAICP)

- Earthquake Engineering Research Institute (EERI) 